\title{
La población de Lepe en los siglos XIV y XV.
}

Los gremios y la industria a través de las antiguas Ordenanzas para el gobierno y regimiento de la villa de Lepe.

\section{Población}

Durante la muy larga permanencia de Lepe bajo el dominio musulmán, ningún grupo de cristianos debió subsistir hasta la $\mathrm{Re}$ conquista, o si lo hubo no debió considerársele acreedor a sus tierras, pues todas ellas, de nuevo la Villa en poder de los cristianos, pasaron a la Orden del Temple (que la conquistaron en unión de los portugueses), de ésta a la Corona y, posteriormente, a los Guzmanes, señores de Niebla; pues, como sabemos, se consideraban caducados los derechos anteriores a la invasión árabe, perteneciendo a los reyes por derecho de conquista todas las tierras ganadas a los musulmanes, sin otra limitación, en cuanto al dominio de aquéllas, que "la de respetar las tierras propias de los cristianos si no habían hecho cosa por que debieran perderlas y la que resultase de las condiciones estipuladas en los tratados a favor de los vencidos" (1).

Los cristianos que llegaron a Lepe, como consecuencia de su reconquista (siglo XIII), portugueses y españoles, constituyeron el núcleo mayor de la población, atraída por las promesas y privile-

(1) Minguijón, cuaderno 2., pág. 185. 
gios of recidos a los que fueran vecinos de la Villa y que en parte vemos recogidos en las "Ordenanzas por donde se rige y gobierna la justicia y regimiento de la Villa de Lepen, que son objeto de nuestro estudio (año 1518 y siguientes).

Después de los portugueses del tiempo de la reconquista de Lepe, quedados en la Villa, otros, procedentes del Algarve, siguieron llegando a ella y a todos los lugares de la comarca, constituyendo una inmigración frecuente y periódica, cuya causa es el trabajo, y así encontramos portugueses en las faenas más rudas, en el campo y en el mar.

Establecidos en el país, llegan hasta nuestros días multitudes de apellidos portugueses mezclados con los españoles, y actualmente, en todo el campo de Lepe, encontramos una numerosa colonia descendiente de Portugal, con fincas propias, producto del ahorro y del trabajo.

Un segundo grupo étnico y, social, más reducido que el anteriormente citado de cristianos, existió en Lepe, que permaneció aislado, sin mezclarse con aquéllos, porque siempre fué rechazado; que tiene estigmas de esclavo (2), pero que no trabaja y vive a costa de los cristianos, los judíos. Sabido es que preferían para vivir los países ricos y los pueblos de señorío, razones que justifican su presencia en Lepe ; dedicados a la usura, ueran mercaderes e vendedores e arrendadores de alcabalas e rentas de achaques... (3), ninguno rompía la tierra..., todos buscaban oficios holgados e modos de ganar con poco trabajo...) (4).

En Lepe constituyeron los judíos, hasta su expulsión por los Reyes Católicos, un núcleo importantísimo de la población, como lo evidencia el hecho de tener aquella Villa, en el siglo xv, la segunda aljama, en importancia, de Andalucía, pues en el "reparti-

(2) En M'oguer y otras villas, los judios más importantes se llamaban a si mismos acriados del señor Marquésn.

(3) Achaque. En el lenguaje jurídico y legal, equivalia antiguamente a multa, y llamábase asi especialmente a la multa o pena pecuniaria que imponía el Concejo de la Mesta a los infractores de las leyes relativas a la ganadería.

(4) Historia de los Reyes Católicos, de Andrés Bernaldes, Cura de los Palacios, citado en La Rábida, del P. Angel Ortega, .O. F. M., t. I, pág. 302. 
miento" hecho en 1464 por Rabbí Jacob Aben-Núñez de lo que las aljamas habían de entregar cada año al Rey, figura la de Sevilla con 2.500 maravedises, la de Córdoba con 1.200, y las de Jerez, Aroche y Lepe con 1.500 maravedises cada una (5).

Mudéjares también debieron existir en cantidad, al menos alarifes, a juzgar por los muchos monumentos que aún hoy admiramos en Lepe, de tal filiación; la interesante Parroquia de Santo Da mingo de Guzmán (principios del siglo xiv), y varios primorosos ajimeces repartidos en distintos edificios particulares.

Un último grupo en la población tuvo Lepe, lo mismo que las demás villas de la comarca, los vulgarmente llamados "morenos"; hombres y mujeres de otra raza, robustos, sufridores del trabajo, importados de distintos lugares de Africa, de los que Ortiz de Zúñiga (6) dice : "Había años que, desde los puertos de Andalucía (7), se frecuentaba navegación a las costas de Africa y Guinea, de donde se traían esclavos negros...; pero desde los últimos del Rey D. Henrique, el Rey D. Alonso de Portugal se había entremetido en esta navegación..., quejándose los de Sevilla, aunque no eran oídos, hasta ahora, en que la guerra fué ocasión de querer recobrar este derecho; y los Reyes desde Valladolid, a 15 de agosto, enviaron a mandar a Sevilla, y a todos estos puertos, que se impidiese aquel comercio a los portugueses, y se armasen navíos para navegar a él : mandato muy bien recibido..., con cuya disposición muy presto salió número de carabelas, y se volvió a entablar aquel comercio tan provechoso." Las villas del Condado de Niebla, el señorío de Moguer $y^{\circ}$ todos los lugares de los Marquesados de Gibraleón y de Ayamonte se abarrotaron de la humana mercancía, cuyos descendientes aún hoy los identificamos en la comarca.

El citado Zúñiga continúa escribiendo y dice : "Eran en Sevilla los negros tratados con gran benignidad desde el tiempo del

(5) El original de dicho importante erepartimiento se conserva en la Biblioteca Nacional (cita de D. Rodrigo Amador de los Ríos, tomo Huelva..., pág. 167)

(6) ORTIZ DE ZÚÑ́IGA, Anales eclesiásticos y seculares de la muy noble ciudad de Sevilla (año 1475, núm. 10).

(7) Los puertos de la costa de las provincias de Huelva y Cádiz y el de Sevilla. 
Rey D. Henrique III, permitiéndoseles juntarse a sus bayles y fiestas en los días feriados y con lo qual acudían más gustosos al trabajo, y toleraban mejor el cautiverio, y sobresaliendo algunos en capacidad, a uno se daba título de mayoral, que patrocinaba a los demás con sus amos, y.con las justicias componía sus rencillas: hállase así en papeles antiguos, y acredítalo una cédula de los $\mathrm{Re}$ yes dada en Dueñas a 8 de noviembre de este año... Por los muchos, buenos e leales e señalados servicios (dice su tenor) que nos habeis fecho, y faceis cada día, y porque conocemos vuestra suficiencia y habilidad y disposición, facemos vos mayoral e juez de todos los negros e loros libres o captivos que están, e son captivos e horros en la Muy Noble y Muy Leal Ciudad de Sevilla a en todo su Arzobispado, e que non puedan facer, ni fagan los dichos negros... ningunas fiestas nin juzgados de entre ellos, salvo ante vos el dicho Juan de Valladolid, negro, nuestro juez y mayóral de los dichos negros, loros y loras; y mandamos que vos conozcais de los debates y pleytos y casamientos y otras cosas que entre ellos hubiere, e non otro alguna, por quanto sois persona suficiente para ello, o quien vuestro poder hubiere, e sabeis las leyes e ordenanzas que deban tener, e Nos somos informados, que sois de linaje noble entre los dichos negros, etc.).

Del nombramiento mentado, de "juez y mayoral" de los negros, queremos destacar que la jurisdicción de dicho juez, por ser la del Arzobispado de Sevilla, se extendía a todo el territorio del Marquesado de Ayamonte, $y$, por tanto, a los negros que moraban en la Villa de Lepe.

En la sociedad de Lepe, desde su reconquista, podemos afirmar que no hay diferencias de clases, a no ser la natural de los esclavos y la impuesta por los judíos, según antes queda apuntado.

No existe otra aristocracia que la señorial, porque a su lado tampoco cabe otra en parangón (8). Pasando por alto los tiempos en

(8) Se desprende de algunos documentos, que los primeros Caballeros establecidos en algunas villas (Niebla, Gibraleón, Palos y otras), a raiz de la reconsquista de las mismas, levantaron sus casas y haciendas al advenimiento del señorío por no acatar un vasallaje distinto al del rey. Esto explica la carta del rey Don Fernan- 
que Lepe estuvo sometida a D. Juan Alonso de Guzmán, primer Conde de Niebla ( +1396 ), a su segundo hijo D. Alonso de Guzmán y al nieto de aquél primer Conde, también llamado D. Juan (tercer Conde de Niebla y primer Duque de Medina Sidonia († 1468), bajo los cuales nada hay digno de mención para nuestro estudio, vemos cómo Lepe, con Ayamonte $y_{1}$ La Redondela, son donadas por el citado Conde D. Juan de Guzmán a su hija D. Teresa de Guzmán en dote, al casarse con D. Pedro de Zúñiga y. Manrique (9), primer Marqués de Ayamonte (1475), que es quien otorgó a la Villa de Leepe sus más antiguas Ordenanzas.

El señorío temporal de los Marqueses de Ayamonte, como el de sus coetáneos los Duques de Medina Sidonia (señor de Sanlúcar, Conde de Niebla) y de Medinaceli (señor de Gibraleón, también algún tiempo de Huelva y de muchas más villas), nada tiene que se parezca a los sistemas más o menos feudales de otras partes; y difícilmente se hallará, en la historia, un régimen similar más amplio, más tolerante y más protector. Lepe, como otras muchas villas, se lo debe todo a sus señores, pues aun cuando a fines del siglo xviri, y más propiamente a principios del xIx, surgieron algunos rozamientos entre el Marqués y el Ayuntamiento, ello hay

do IV a la villa de Gibraleón, de 10 de diciembre de 1304, al otargársela el monarca, a adon Alfonso su hermano, hijo del Infante don Fernando de la Cerdas y de doña Blanca de Francia, hija de San Luis, carta en la que se manda al Concejo de la Villa que a pesar de la repugnancia que mostraba en apartarse de la Corona, reciba por su señor a Don Alfonso (Rodrigo Amador de los Ríos, Huelva, apéndice núm. XI). $\mathrm{Y}$ los que de Niebla dice Rodrigo Caro: Estuvo Niebla, después que el rey Don Alfonso el Sabio la ganó a los unoros..., ennoblecida y habitada de los caballeros y soldados que se habian hallado en su conquista..., hasta que el año de 1369, estando el rey Don Enrique II en Sevilla, casó a doña Beatriz de Castilla, su hija, con don Juan Pérez de Guzmán, y le dió... esta Villa... Desde este tiempo... Jos caballeros de Niebla no sufrieron ser vasallos de ningún señor que no fuese el rey de Castilla..., y se fueron a vivir... a Sevilla y parte a Jerez de la Firontera y otros lugares de realengo, y esta fué la primera disminución de esta noble y antiquísima villa...

(9) Es hijo mayor de don Alvaro de Zúniga, Conde de Plasencia y de Ledesma, enconces señor de muchos pureblos, entre ellos de Béjar y de Arévalo, y en $\mathbf{1 4 8 5}$ primer Duque de Béjar por gracia de los Reyes Católicos, ducado que no heredó don Pedro por morir en 1484, cuando aún vivía su padre. 
que atribuirlo a los aires ya reinantes procedentes de Francia, siendo indiscutible la obra social, cristiana y realmente paternal realizada por el Marquesado en favor de la Villa, según sè irá exponiendo a través del estudio de las antiguas Ordenanzas dadas a Lepe para su gobierno y regimiento.

A fines del siglo $\mathrm{xv}$ y principios del xvI era aquélla una Villa de labradores, ganaderos, gentes de la mar y con alguna industria, pletórica de vida y de salud, ley suprema del bienestar social; adquiriendo considerablé actividad, a partir del descubrimiento de América, ya que en todos los viajes de Colón, y en los posteriores, participaron los hijos de Lepe, mereciendo ser recordada, especialmente, la expedición de Juan Díaz de Solís (8 de octubre de 1515) (10).

Una prueba del florecimiento de Lepe, en la época a que nos venimos refiriendo, esi el enriquecimiento, día a día, de su Parroquia (11), el contar con cuatro conventos (12), con las capillas de los gremios, con varios mesones y con un hospital para pobres, que se menciona en las Ordenanzas (Ordenanza de (bastardos), 19 junio 1526. Ordenanza sobre venta de higos por quital, 19 junio 1526. Arancel de Mesoneros, 23 septiembre 1532).

(10) En otro momento del estudio que estamos realizando nos ocuparemos, concretamente, de aLepe y las cosas de la mar....

(11) Hasta el saqueo de julio de 1936 existieron en este templo infinidad de obras artísticas que la piedad de los fieles fué acumulando en aquél, hasta convertirlo en un vendadero arelicario de artes; recordando ù alto relieve en mármol (s.' xIv), un tríptico de Juan Van Eyck (s. xv), varias imágenes del siglo xvir (citamos una Irimaculada, catalogada como muy bella obra del círćlo Montañesino), retablos de la misma centuria, un lienzo atribuido a Zurbarán (altar de Animas), rejas de los siglos xvi y xvIr, bellos azulejos (s. xVIr) y un órgano similar al del monasterio de Guadalupe.

(12) aEn el archivo del Arzobispado consta, en relación del Arzobispo Fray Pedro de Tapia (año 1655), que entonces había en Lepe dos conventos de frailes D.o. minicos (uno de ellos, Nuestra Señora de Gracia), con catorce religiosos en total; el mayor era el que ocupaba el edificio que hoy tiene fachata a la calle Real... En la sobredicha relación... se dice, que había también un convento de Recoletos de San Francisco, con veinte religiosos, en EL TERRON...; y un convento de monjas Dominicas, con cincuenta religiosas». (Del folleto del autor, El Templo Parroquial de Santo Domingo de Guzmán, de Lepe. Huelva, 1953.) 


\section{LOS GREMIOS Y LA INDUSTRIA}

Sabemos cómo en Castilla reaparece la industria en los siglos XI y xII, conforme progresa la Reconquista, organizándose los industriales de un mismo oficio en el ambiente familiar, económico y religioso de los "gremios", que, se desarrollan a la sombra de los privilegios municipales; pues bien, en lo que a Lepe concierne, el testimonio más antiguo sobre organización gremial está contenido en las "Ordenanzas que el Conde nuestro Señor mandó q tengâ los çapateros el año de mill $y$. quis $y$ diez y ocho años' (folios 15 bis a 18).

Del carácter religioso de los gremios ha llegado hasta nuestros días, en lo que a Lepe se refiere, el testimonio, recogido en las tan mentadas Ordenanzas de la Villa, por el que los componentes de su Cabildo, reunidos en 25 de mayo de 1540, accediendo a lo pedido por el gremio de zapateros, zurradores y curtidores ; confirman las Ordenanzas de aquéllos, "las quales hordenanzas teníamos confirmadas por el Cabildo desta billa y así las teníamos y guardábamos las quales senos perdieron por ser viejas». Según las tales Ordenanzas, los zapateros de Lepe tenían el privilegio de costear las fiestas del Santísimo Corpus Christi, imponiendo a "todas las personas estranjeras que de qualquiera partes venían a poner tienda del dho oficio y la ponían en esta billa heran obligados a pagar dos reales de cada un año no siendo bezinos estos, ha de pagar, el señor de ia tienda y si un maestro estuviere con el tal señor este pague como obrero". Además, todos los de la Villa del oficio, "lo husen poco o mucho", tenían que pagar medio real "cada uno para los gastos de la dicha fiesta", entregándose todo lo cobrado "al mayordomo que fuere aquel año...", repartiéndose todos los gastos entre los zapateros, zurradores y curtidores de la Villa:

También han llegado hasta nosotros, como manifestación del aspecto religioso de los gremios de Lepe, otros testimonios ; algunas de las capillas de sus cofradías y los nombres de sus Patronos. Así, la capilla de San Antonio, del gremio de pescadores (en calle San Antonio, edificio esquina a la de Arcos, convertido en vivien- 
da) ; la de los agricultores, consagrada como en tantas otras localidades a San Sebastián (al final de la calle de igual nombre), y. la de la Caridad, junto al actual mercado, con su graciosa espadaña.

La jerarquía, establecida en forma general en los gremios, también existió, naturalmente, en Lepe, pues así se desprende de las Ordenanzas de zapateros, de 1518 (folios 15 bis a 18), y de la de toneleros, de 1523 (folios 4 y 7), en las que se habla de "oficiales"); y de las Ordenanzas de la fiesta del Santísimo Corpus, de 25 de maya de 1540, que, refiriéndose también a los zapateros, habla de "maestro" y de "oficial", con la lógica deducción de existir retribuciones distintas y normas reguladoras de los ascensos de oficial a maestro, según consta de otras localidades.

El ingreso en la categoría necesaria para ejercer la industria, mediante examen, lo vemos establecido y regulado en la citada Ordenanza de toneleros (folios 4 y 7), de 14 de mayo de 1523, acordada por el Cabildo, reunido, precisamente, para fijar y nombrar los vecinos que "pueden tener plaça de toneleros y son ábiles y suficientes para ello, por quanto enesta billa sea fecho mucha vasija muy mal fecha e a daño de los mercaderes y labradores...".

Luego, se dice: "...y el que obiere de poner plaça ha de tener licencia de rregimie $^{\circ}$ desta billa y ha deser examinado $y$, visto su examen por el rregmin $^{\circ}$ desta billa y cabildon. Que cuando algún oficial se tuviere que examinar, que sea por un Regidor que, a la sazón, fuere Diputado, presente el Escribano de Cabildo y con dos oficiales toneleros de la Villa. También se dispone: "Que ninguna persona rrebata ninguna basija sin ser examinado y tener licencia para ello, so pena de seis cientos mrs, el tercio para quien lo acusare.")

Venimos citando, como intimamente ligadas a la industria de Lepe, de manera especial, en los siglos xvi y xvir, dos Ordenanzas, que son : la de zapateros, de 1518, y la de toneleros, de 1523, algunos de cuyos preceptos hemos comentado. Vamos ahora a examinar dichas dos Ordenanzas en particular.

Ordenanza de zapateros.-Sus disposiciones las agrupamos para un más perfecto conocimiento, como sigue: a) Que tienden a su- 
primir la clandestinidad. b) Para procurar el adecuado uso de los materiales, a fin de evitar fraudes. c) Sobre la perfección del trabajo. d) Para que no haya engaño. $e$ ) Tendentes' a asegurar la existencia de buenos materiales; y f) Sobre penas para los infractores.

a) Sobre la clandestinidad y, a la par, procurar el uso de las pieles en debida forma, se dispone: 1. "Que qualquiera que tuviere a curtir cueros para suelas que al tiempo que las quisiere rretornar sea obligado a lo hazer saber al diputado quel concejo eligere pára. queltal diputado conel beedor bean si están para rretornarn; lo mismo que cuando: 2. "Alguno quisiere sacar los dichos cueros... de los tiestos o logar donde los tuviere para bender o labrar que sea obligado a llamar al diputado..." para que con el veedor "bean si están bien cortidos y tales que se deben sacar". En ambos casos, los contraventores debían perder el cuero y pagar como pena sèiscientos maravedises.

b) El debido empleo de materiales, en evitación de fraudes a los compradores, se regula no sólo, según antes decimos, con la intervención del Diputado del Concejo y del Veedor, sino al prohibirse: 3. Que los zapateros "usen suelas» lamidas, ni desfloradas (13), ni herradas (14), ni quemadas...., debiéndose utilizar tan sólo suelas de buey o vaca y no de asnos, ni de caballos. 4. (Pena de doce maravedises por par y pérdida del calzado). También se dispone: 6. Que los zapatos de vaca se cosan con guita y no con estopa ; se prohibe : 8. Que se labre calzado alguno, ya borceguíes, ya zapatos o zapatillas con puntos arriba, salvo de cordobán y de badana y no de borregos, ni de otros cueros semejantes; se fija para ambos casos la pena de pago de doce maravedises y la pérdida del calzado labrado contra lo dispuesto. 11. Que los cueros, de vaca o bueyes o chivatos o badana, ya sean para labrar o para vender, estén bien curtidos y zurrados y no quemados y con otros desperfec-

(13) Pieles clamidas» y adesfloradas» son las que tienen alguna de sus caras, especialmente la externa, raspada, más en las damidas que en las desfloradas donde el desperfecto es menos profundo.

(14) Pieles aherradas» son las que contienen los ahierros de las ganaderías que, como es sabido, queman la piel. 
tos, bajo la pena de perder y pagar por cada cuero y pedazo o par de suelas, doce maravedises; por lo que: 12. Ningún calzado, de vaca, de cordobán o de badana, se labre estando mal curtido (igual pena que en el caso anterior); y que ningún cuero para suelas se curta "con arraihan" (15). 13. Ni el cordobán ni la badana "se curtan 'sino con su maque" (16). 14. (Pena de seiscientos mirs. y pérdida de la piel).

c) La perfección en el trabajo también es objeto de algunos preceptos: 2, 7 y 9 . Tales, como el ya'mencionado, de que si alguno quisiera sacar cueros para vender o labrar, ha de llamar al Diputado y Veedor para que se utilicen o no, sil están bien curtidos. 7. Que los zapatos de vaca deben llevar contrafuertes y los de cordobán o badana tengan aquéllos, y además, barretas y chapetas. 9. Prohibiéndose que los borceguíes de cordobán lleven plantillas de badana. En ambos casos, perderán los infractores los zapatos y pagarán doce maravedises por cada par.

d) Hay un precepto: 10. Curioso, cual es, que todo vendedor de cuero o de calzado venía obligado: a decir al comprador si lo vendido era vaca o buey o cordobán o badana, o lo que fuere, "sin se lo preguntar porque no benda una cosa por otra so pena de lo perder y pague... doze mrs.....).

e) Para asegurar a la industria local la existencia de buenos materiales y géneros, dicen las Ordenanzas: 15. Que nadie saque de Lepe ningún arraihan (pena, cinco mil mrs.) ; y 16. Que de fuera, nadie traiga soleria "sino que sea de arraihan so pena de las perder y pagar dos mill mrs....), y que tampoco se traiga calzado de fuera "...sino que sean las suelas de arraihan para vender so la dhâ pena.»

f) Sobre las sanciones establecidas y que hemos dejado señaladas al exponer cada caso, sólo queremos hacer resaltar que es general la pérdida del material usado en malas condiciones o clandestinamente, y de lo fabricado, contraviniendo las Ordenanzas, sin

(15) ARRAIHAN», asi escrito, como figura en las Ordenanzas que estudiamos, es lo mismo que carrayán», arbusto usado para el curtido de pieles.

(16) SUMAQUEø es el arbusto czumaques, dico en tanino, que se usa por los zurradores como curtiente. 
perjuicio de las penas pecuniarias establecidas, tratándose de calzado, doce maravedises por par, elevadas considerablemente en los casos de introducciones de malos géneros en la Villa.

Ordenanza de toneleros.-Fué acordada, según antes se ha dicho, por el Cabildo, reunido el 14 de mayo de 1523, para fijar el número y acordar los nombres de los vecinos que "pueden tener plaça de toneleros y son ábiles y suficientes para ello por quanto enesta billa sea fecho mucha basija muy mal fecha...n.

Prescindimos del orden en que están redactados sus preceptos, para procurar hacer una exposición de los mismos, ciertamente ordenada, reunidos, conforme al fin que los motiva, en la siguiente forma: a) Para procurar la suficiencia profesional de los toneleros. b) En evitación de la clandestinidad y del intrusismo profesional. c) Sobre las características de las vasijas; y $d$ ) Tendentes a evitar fraudes.

u) La capacidad profesional aparece garantizada al disponerse, después de nombrar el Cabildo los once primeros maestros que podían construir vasijas, "...que otra ninguna persona desta biila pueda poner plaça de tonelero, so pena de tres mill mrs... y el que obiere de poner plaça ha de tener licencia de rregm $^{\circ}$ desta billa y ha deser examinado y bisto su examen por el rrgim $^{\circ}$ desta billa y cabildo.n

"Que quando algún oficial se oviere de esaminar que sea por un rregidor que a la sazón fuere Diputado presente el escrivano de Cabildo y con dos oficiales..." 10. "Que ninguna persona rrebata ninguna basija. sin ser exsaminado y tener licencia para ello. so pena de seis cientos mrs....).

b) En evitación de la clandestinidad y del intrusismo, no sólo toma el Cabildo el acuerdo de nombrar los once primeros maestros toneleros, a partir del 14 de mayo de 1523 , fecha de la más antigua reglamentación llegada a nuestros días, y acuerda, también, que cuantos quieran "poner plaça" han de examinarse y tener licencia, según antes se dice, sino que, además, se dispone: 9. "Que todos los señores de plaça tengan sus marcas de fuego y que ni salgan de su casa. ninguna. basija sin ser señalada. de su marca. de fuego y de la marca de la billa. y que tengan las marcas diferençaadas 
por que sean conoscidas so pena de quis mrs. y el caxco quemado por falso."

Finalmente, se dispone que haya en la Villa dos veedores, que "lleven de cada basija un maravedí y que sean themidos de rrequerir y ber las basijas y marcar doss vezes cada semana. miércoles y sábado...).

De 26 de julio de 1526 hay una Ordenanza dada por el Marqués, sobre (ibastardos) (folios 1 vuelto y siguientes), en la que se contiene una disposición mandando que: "...pongais beedores de la basija así para el tamaño como para la madera...) para que no haga mal vino, y cuando el tamaño no sea el debido y la madera mala, "...mando que la tal basija sea luego quemada e quel tonelero que la hizo pague por cada pipa o tonel de pena trezientos mrs....".

c) Las características de las vasijas, así como la perfección en su construcción, motivan un grupo de disposiciones que vamos a exáminar. Las botas y las pipas no podían tener de banda más de un palmo, y el tonel y el cuarto un palmo (pena, $600 \mathrm{mrs}$.) ; el tonel había de tener de lías en el bajo dos palmos y medio, cuatro arcos, y en la cabeza otros cuatro arcos, llegando las lías a cabilla a cabilla ; las botas y pipas “de dos palmos de lías y en lo demás de la misma manera... y el quarto dos palmos de lías en el bajo y en la cabeza tres... so la dicha penal. Que ni la pipa, ni el tonel para bastardo pudieran tener siete duelas de çamago (17) "a la boca y no más que las cinco duelas de çamago llegue a las cabezás y las dos duelas no puedan llegar, so pena de quís mrs... y que la basija de estas que de otra manera se hiziere que sea quemada e abida por falsa y en los fondos que no tengan ningún çamago so la misma pena..." "Y tem que ninguna basija hagan sin barras $\mathrm{y} \cdot$ que las barras de botas y pipas tengan cada barra tres canillas y del tonel quatro... y del quarto dos o tres canillas so pena de trezientos mrs....).

"Que cada basija destas, las pipas y toneles y quartos sean de

(17) Se denomina asamagon a la parte endeble o inútil de algunas piezas de mardera, no conveniente para la construcción. 
la pared e mole e tamaño de sevilla y las botas del tamaño y manera de sant lucar, de Barrameda, so pena de quis mrs. y la basija sea bicla por falsa y quemada.»

d) Para evitar fraudes, se dice en las Ordenanzas, a más de lo antes consignado sobre marcas de fuego de las vasijas, que de éstas, toda la "que se hiziere sea estanca y que si se saliere por brocas algunas o por duelas quebradas, rreguardadas o por nudo que fuere mal rreguardado o no rreguardado y que ningun ${ }^{\mathbf{s}}$ duela de nudo se pueda hechar sino a la boca y no más de dos duelas. junto a las duelas de los samagos y que en cada caxco ora sea con çamago ora sin el, no pueda, hechar más de doss duelas con nudos y por estas cosas susodhâs o por otras quales quier quel caxco o vasija se saliere quel señor dela plaça sea obligado a pagar la pena y el daño y la bota sea que mada y le quede su rrecurso contra el oficial que la hiziere para le pedir el $\mathrm{dz}^{\circ}$ que contra el tuviere").

Por último, la existencia en Lepe del oficio de "veedor" de las vasijas, tiende igualmente a descubrir todo posible fraude del gremio de toneleros, ya sea en el empleo de maderas, en malas condiciones, ya en lo que afecte a la capacidad y construcción de los cascos.

e) En cuanto a las sanciones contenidas en las Ordenanzas que estudiamos, se destaca la quema de la vasija y la declaración de ser falsa, en todos los casos, de infringirse las normas que se señalan para su construcción y para cuando se omiten las marcas a fuego del dueño y de la Villa.

\section{Lưis Martf́nez SÁnchez,}

Correspondiente de la Real Academia de la Historia. Secretario de 1. ${ }^{\text {a }}$ categoria, de Administración Local. 